Check for updates

Cite this: RSC Adv., 2018, 8, 41347

\title{
Rapid decoloration of azo dye Direct Blue 6 by AlCrFeMn high entropy alloy
}

\author{
Shikai Wu, Ye Pan, D* Ning Wang, Weiji Dai, Jie Lu and Tao Lu \\ In recent years, high entropy alloys (HEAs) have attracted a lot of attention from researchers due to their \\ outstanding mechanical properties, but there are few reports about their functional performance. The \\ development of new functional applications of HEAs is a challenging, but very meaningful topic. The \\ decoloration of azo dye Direct Blue 6 (DB6) using equiatomic AlCrFeMn HEA synthesized by ball-milling is \\ reported in this study. Ball-milled (BM) AlCrFeMn HEA shows excellent performance in the decoloration of \\ DB6, 3 times faster than BM MgZn-based glassy powders and AlCoCrTiZn HEA, which are reported as the \\ best among the metallic glasses and HEAs so far, respectively. The effects of initial $\mathrm{pH}$, initial temperature \\ and dye concentrations on the decoloration efficiency during reaction are systematically studied. This work \\ can greatly expand the applications of HEAs, especially the application of their functional properties.
}

Received 2nd August 2018

Accepted 29th November 2018

DOI: $10.1039 / \mathrm{c} 8 \mathrm{ra06496b}$

rsc.li/rsc-advances

As a new type of multi-principal-element alloy, HEAs are

\section{Introduction}

Azo dyes are the most dominant artificially synthesized dyes that are used in various types of industries such as ink, paper, leather, plastic, textiles, etc. ${ }^{1-3}$ However, the overuse of azo dyes has caused serious environmental and social issues. ${ }^{\mathbf{4 , 5}}$ For instance, azo dyes are precursors to various carcinogens, which are a significant threat to people's health; besides, only a small amount of azo dye in the effluent stream is enough to cause a startling color change in a water body and seriously affect the photosynthesis of aquatic plants or the growth of fish in the water. Worst of all, azo dyes are very difficult to remove from aqueous solutions. ${ }^{6-10}$ Due to the potential harm to environment and people's health, pollution of the sewage by azo dyes is always a concern for academic researchers. ${ }^{11,12}$ Various kinds of physical, chemical and biological methods are applied for the treatment of wastewater polluted by azo dyes. ${ }^{13-18}$ Among these methodologies, zero-valent metals such as magnesium, iron, aluminum or zinc have shown great promise for the decoloration of azo dyes due to their environment friendliness, low cost, high-efficiency, simple operation and superior ability to cleave dye molecules into products that are more agreeable to mineralization in the biological treatment process. ${ }^{\mathbf{1 9 - 2 1}}$ Zero-valent metals have many disadvantages, for example, zero-valent magnesium powders are overconsumed due to their poor corrosion resistance and zerovalent iron (ZVI) powders tend to agglomerate and lack stability. ${ }^{22,23}$ Therefore, it is urgent to develop environment friendly, easy to prepare, low cost, strong corrosion resistant alloy materials with a strong ability to decolorize azo dyes.

School of Materials Science and Engineering, Southeast University, Jiangsu Key Laboratory for Advanced Metallic Materials, Nanjing 211189, PR China. E-mail: panye@seu.edu.cn; Fax: +8625 52090681; Tel: +862552090681 metastable materials lying far from the equilibrium state, which endows HEAs with many excellent properties that are unachievable in crystalline alloys. ${ }^{24-26}$ HEAs have received a lot of attention in the material science community in recent decades, but the study of HEAs has focused on the mechanical properties. Z. Y. Lv et al. report that AlCoCrTiZn HEA exhibits a prominent efficiency in degrading azo dye Direct Blue 6 (DB6). ${ }^{27}$ Inspired by this study, we decided to design and prepare new compositions of HEAs with good decoloration performance towards azo dyes. Ball milling is a well-known and simple method for the synthesis of HEAs, and BM HEA powders will have larger specific surface area and more active sites than block HEAs. The purpose of this study is to develop new HEAs with high-efficiency performance in decolorizing azo dyes. The decolorization of azo dye DB6 by the newly designed AlCrFeMn HEA is reported in this study. Our findings will certainly extend the applications of HEAs as functional materials.

\section{Experimental}

\subsection{Materials and reagents}

Elemental powders of $\mathrm{Al}, \mathrm{Cr}, \mathrm{Fe}, \mathrm{Mn}$ with high purity (>99.9 wt\%) and particle sizes between 1-10 $\mu \mathrm{m}$ were used as raw materials to synthesize equiatomic AlCrFeMn HEA. Direct Blue 6 (DB6, $\mathrm{C}_{32} \mathrm{H}_{20} \mathrm{~N}_{6} \mathrm{~S}_{4} \mathrm{O}_{14} \mathrm{Na}_{4}$ ) was purchased from Hailan Chemical Pigment Co. (Tianjin, China). The zero-valent Al, Cr, Fe, Mn powders (purity $>99.9 \mathrm{wt} \%$ ) were provided by Sino New Material Co., LTD. (Beijing, China). The ball milling process was carried out in a high energy planetary ball miller at $400 \mathrm{rpm}$ with a ball to powder ratio of $25: 1$. Zirconia jars and balls were used as the milling media and stearic acid was utilized as the process controlling agent. The ball milling 
program was set for periods of 50 minutes of rotation followed by 10 minutes rest in order to prevent the powders from overheating, polymerizing or adhering to the milling balls and the inner wall of the container. High purity argon was charged into each ball jar before ball milling to prevent the raw powders from being oxidized. After $50 \mathrm{~h}$ of processing, the samples were all taken out from the zirconia jars for further characterization. For each trial, AlCrFeMn powders were added to a beaker containing $200 \mathrm{~mL}$ of azo dye DB6 solution for reaction. The beaker was placed in a water bath device with a constant temperature and the dye solution was stirred at a fixed speed during the reaction. For each time, about $2.5 \mathrm{~mL}$ solution was taken out for testing. The $\mathrm{pH}$ values of the azo dye solution was regulated by adding $0.1 \mathrm{M} \mathrm{HCl}$ solution or $0.1 \mathrm{M}$ $\mathrm{NaOH}$ solution. Distilled water was used as the solvent in this study.

\subsection{Characterization methods}

The morphology and size distribution of the powders were studied by scanning electron microscopy (SEM, JSM-7100F) and the compositions of the samples were examined by EDS equipped on the SEM. The crystal structure of the samples was studied by X-ray diffractometry (XRD, D8 Advance, CuK $\alpha$ ) and FEI F20 transmission electron microscopy (TEM, Tecnai). The surface area analysis was tested by the Brunauer-Emmett-Teller (BET, 3H-2000BET-A) and the statistic distribution of the particle sizes was obtained by laser particle analyzer (FJUL1076). The UV-vis absorption spectra (TU-1810) were collected to evaluate the decoloration activity. The concentrations of the metal ions in the dye solution were detected by inductively coupled plasma atomic emission spectroscopy (ICP, PE ICP8000) and a digital pH meter (FE20, Mettler Toledo) was used to measure the $\mathrm{pH}$ values of the DB6 solution. An electric mechanical agitator (JB90-D) rotated at a certain speed to distribute the HEA powders uniformly in the dye solution.

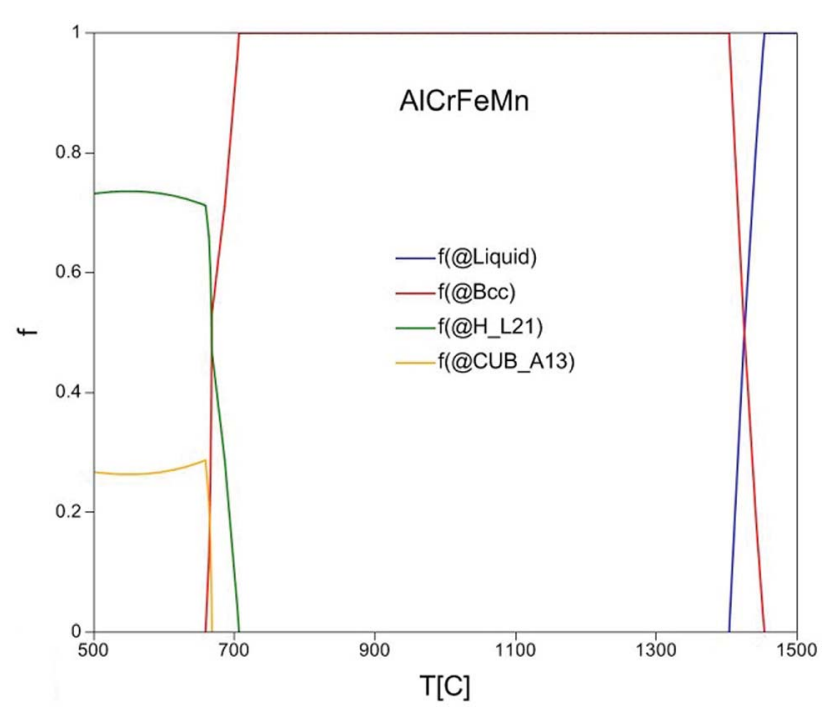

Fig. 1 The phase diagram of AlCrFeMn calculated by software "Pandat".

\section{Results and discussion}

\subsection{Alloy composition design and preparation}

The compositions of alloys have a great influence on the decoloration performance and suitable elements must be selected to synthesize alloys. The alloy composition of AlCrFeMn in this study is motivated by the good performance of metals such as AlCoCrTiZn HEA, Al-based metallic glass alloy, Mn-Al binary alloy, ZVI, etc. ${ }^{27-31}$ As shown in Fig. 1, according to the calculation result by thermodynamic software "Pandat", equiatomic AlCrFeMn only contains single body-centered cubic (BCC) solid solution structure phase between $650{ }^{\circ} \mathrm{C}$ and $1350{ }^{\circ} \mathrm{C}$. This result indicated that equiatomic AlCrFeMn is favored and easily forms the single BCC solid solution structure. Equal proportions of raw metal powders of $\mathrm{Al}, \mathrm{Cr}, \mathrm{Fe}, \mathrm{Mn}$ with a total of 10 grams are weighed, and then AlCrFeMn HEA was prepared by a planetary high energy ball mill.
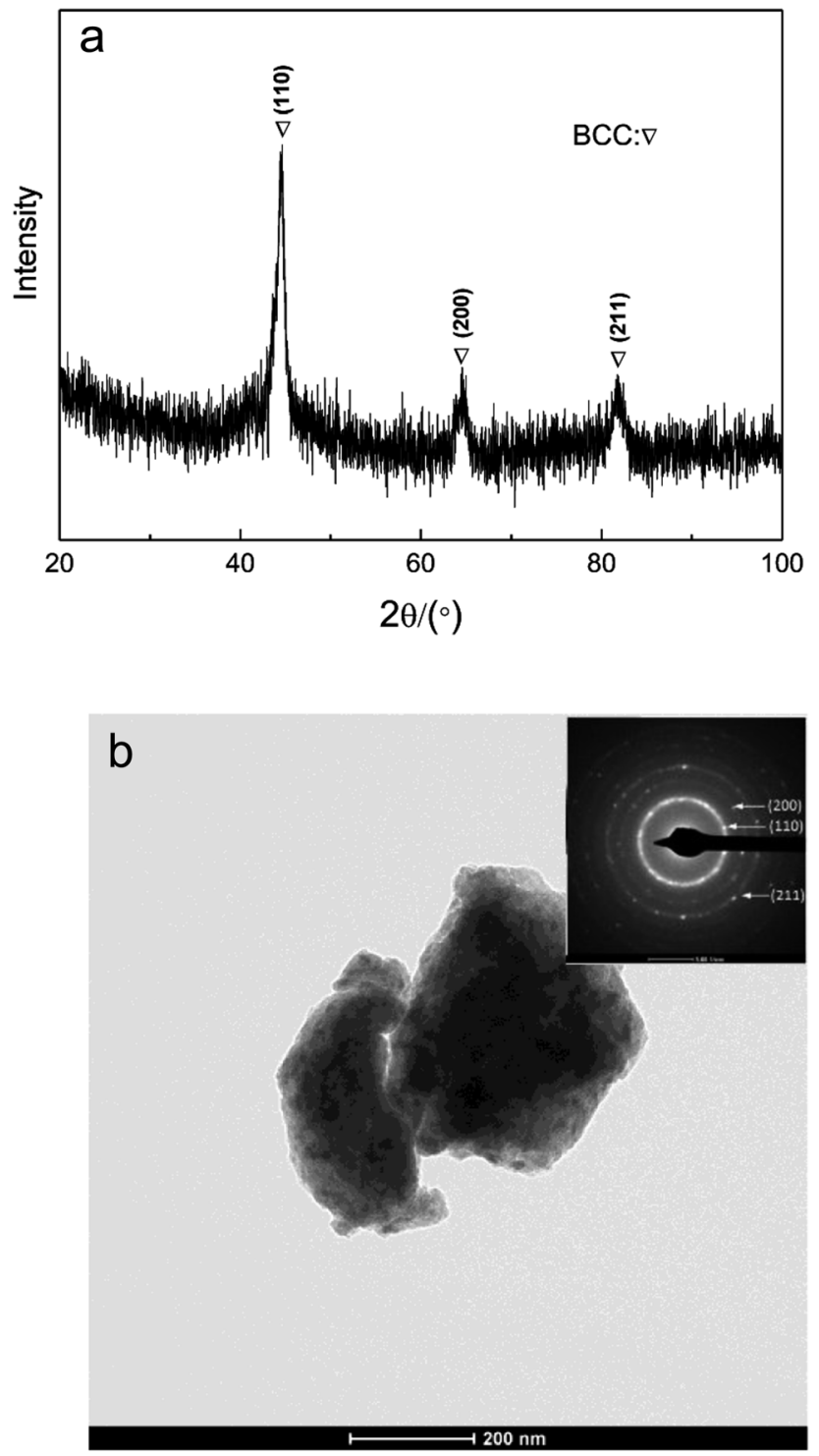

Fig. 2 (a) X-ray diffraction curve of AlCrFeMn HEA before decoloration (b) TEM bright field image of AlCrFeMn HEA before decoloration and the corresponding selected area electron diffraction pattern. 


\subsection{Characterization of samples before decoloration}

The XRD curve of AlCrFeMn is depicted in Fig. 2a, demonstrating the presence of a single BCC solid solution phase in AlCrFeMn and the corresponding crystal surfaces of the peaks are (110), (200) and (211), respectively. The structure of AlCrFeMn is further characterized by transmission electron microscopy (TEM) bright field images (Fig. 2b) and its corresponding selected area electron diffraction (SAED) pattern (inset of Fig. 2b). The good catalytic or degradation properties of many nanostructured materials are distinctly dependent on their crystallite size, morphology and distribution. As can be seen from Fig. $2 b$, the particles are only a few hundred nanometers in size and the corresponding crystal faces are shown in the inset of Fig. 2b. As depicted in Fig. 3a and b, the particle sizes show a relatively uniform distribution and the surface of the powders is rough and full of many corrugations, which is a typical morphology of powders obtained by ball milling. The surface morphology of AlCrFeMn powders indicate existence of abundant active sites, which favors the high-efficiency decolorization performance of AlCrFeMn discussed below. The EDS analysis result in Fig. 3c reveals that the as-produced BM particles are composed of all the elements and the ratio of the four elements of the sample is approximately equal to $1: 1: 1: 1$, which is in good agreement with the nominal composition. Fig. $3 d$ shows that the average size of the AlCrFeMn powders is about $4.2 \mu \mathrm{m}$ and most particles are between 1-10 $\mu \mathrm{m}$ in size. To understand the high decoloration efficiency of AlCrFeMn, the specific surface area
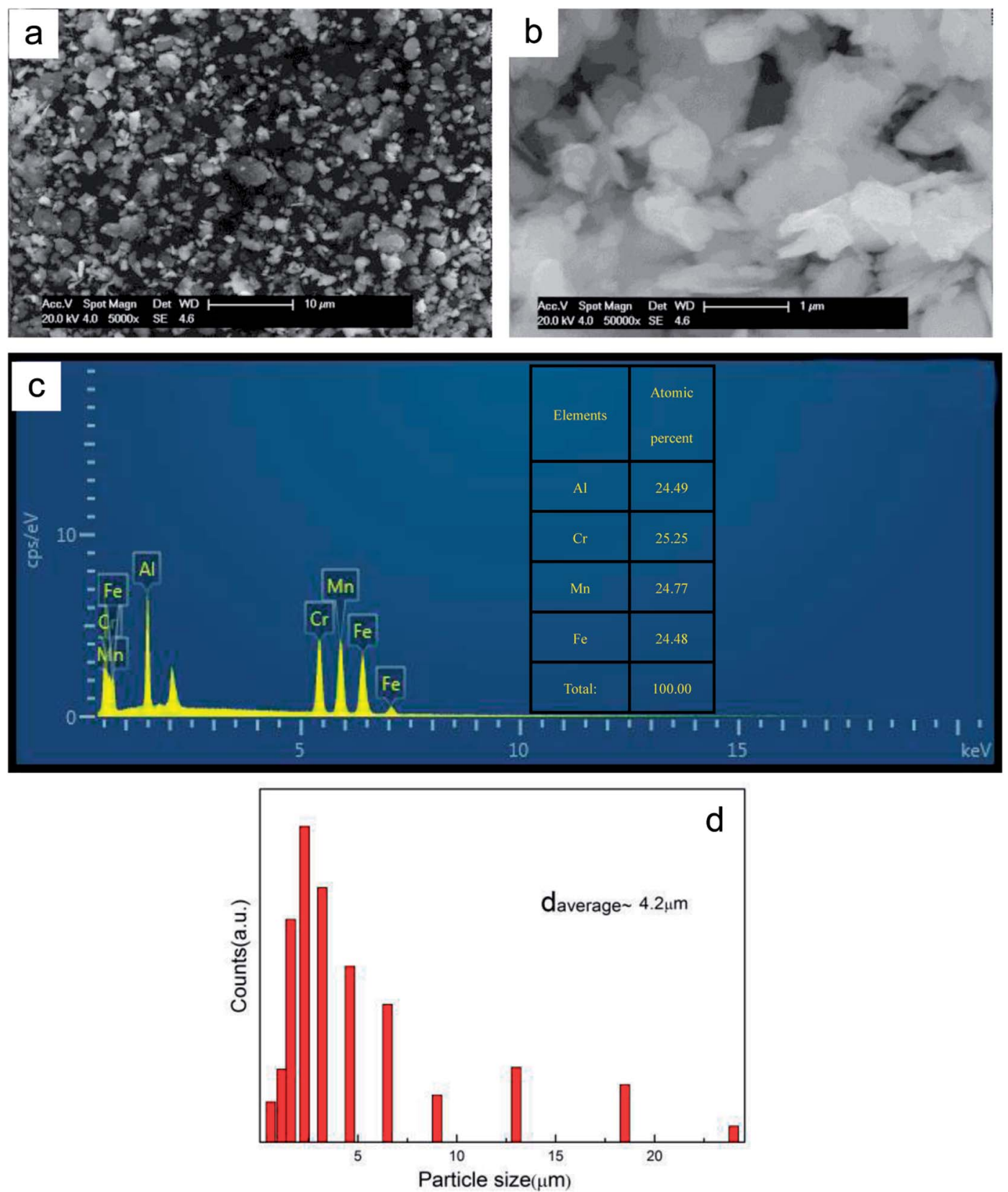

Fig. 3 (a) and (b) SEM images of the AICrFeMn HEA before decoloration (c) EDS analysis result of the actual compositions of AICrFeMn HEA before decoloration (d) size distribution of AlCrFeMn HEA powders after being milled for $50 \mathrm{~h}$. 
of the powders was measured and the average specific surface area of AlCrFeMn is $2.68 \mathrm{~m}^{2} \mathrm{~g}^{-1}$.

\subsection{Comparison with other alloy materials}

Herein, the concentration of the DB6 solutions is $200 \mathrm{mg} \mathrm{L}^{-1}$, while the alloy dosage is different for different agents, i.e., $6 \mathrm{~g}$ $\mathrm{L}^{-1}$ for AlCrFeMn HEA powders, $6 \mathrm{~g} \mathrm{~L}^{-1}$ for BM G-MgZn, and $13.3 \mathrm{~g} \mathrm{~L}^{-1}$ for AlCoCrTiZn, G-FeSiB and BM G-Fe. Except for the alloy dosage, other experimental conditions are the same. The total decoloration time of DB6 by AlCrFeMn is only $0.25 \mathrm{~min}$ as presented in Fig. 4. The BM MgZn-based glassy powder is the highest performing material reported in metallic glasses to date, which needs 0.78 min to degrade DB6. ${ }^{32} \mathrm{BM}$ AlCoCrTiZn is the best material reported among HEAs so far, which requires $0.83 \mathrm{~min}$ and its dose is more than two times that of AlCrFeMn in this study. ${ }^{27}$ In particular, the BM G-MgZn is about 20 times faster than the BM Fe-based glassy powders. ${ }^{16}$ The degradation efficiency of the BM Fe-based glassy powders is about 200 times faster than that of the widely used commercial ZVI powders. ${ }^{16}$

\subsection{Decoloration experiments under different reaction conditions}

3.4.1. Effect of dye concentration. If the AlCrFeMn powder dosage is too high, the degradation time is too short to monitor, so the dosage of AlCrFeMn is reduced in the following experiment. The decoloration of azo dye DB6 is described by the means of UV-vis absorption spectroscopy in this study. Because of the complex structure of DB6, the decoloration process is difficult to analyze. The purpose of this study is to monitor the decolorization process without discussing the intermediate products and predict only the final products of the reaction. The UV-vis absorption spectra of the decoloration of azo dye DB6 by $0.5 \mathrm{~g} \mathrm{~L}^{-1}$ AlCrFeMn is presented in Fig. 5a. The concentrations of the dye solution are proportional to the intensity of the absorption peak. It shows that the whole decolorization process is completed in about $36 \mathrm{~min}$ and the absorption peak is at

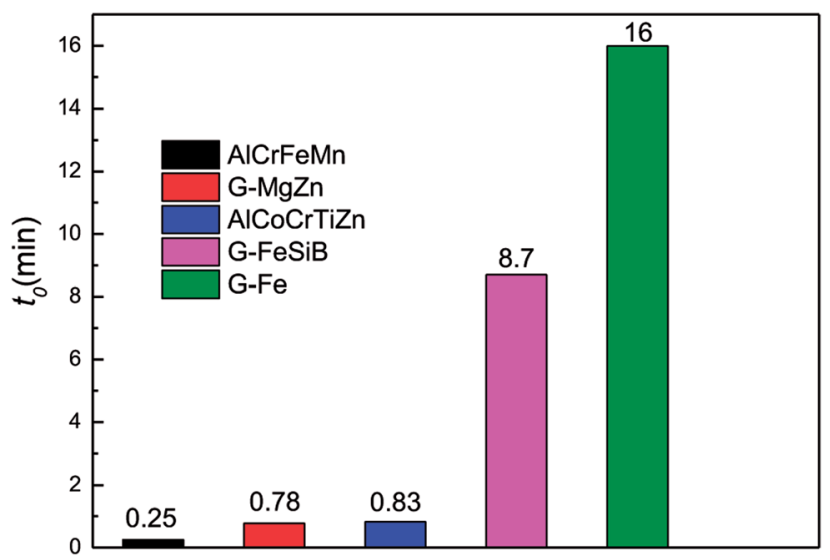

Fig. 4 Comparison of the reaction efficiencies of different powders. Herein, the concentration of all the DB6 solutions is $200 \mathrm{mg} \mathrm{L}^{-1}$, while the dosage is different for different agents, i.e., $6 \mathrm{~g} \mathrm{~L}^{-1}$ for $\mathrm{AlCrFeMn}$ HEA powders, $6 \mathrm{~g} \mathrm{~L}^{-1}$ for BM G-MgZn, and $13.3 \mathrm{~g} \mathrm{~L}^{-1}$ for $B M$ AlCoCrTiZn, G-FeSiB and BM G-Fe. 16,27,33 about $572 \mathrm{~nm}$. In the visible light region $(400-750 \mathrm{~nm})$, at $t=$ $0 \mathrm{~min}$, the curve represents the absorption spectra of DB6 solution without HEA powder treatment. As known to us, the " $-\mathrm{N}=\mathrm{N}-$ " bonds are the most active bonds and chromophoric groups in azo dye molecules, and the cleavage of " $-\mathrm{N}=\mathrm{N}-$ " bonds leads to the decoloration of azo dyes. As illustrated in Fig. 5a, the absorption peak becomes weaker with the addition of AlCrFeMn powders. The intensity of this absorption peak decreases with an increase in reaction time. In the ultraviolet light region (200-380 $\mathrm{nm})$, the characteristic peak at $230 \mathrm{~nm}$ and $320 \mathrm{~nm}$ correspond to the benzene ring and the naphthalene ring, respectively. The two peaks disappear in the decoloration process, and there is no new peak of the by-product during the reaction, which suggests successful decoloration of DB6 solution. By the UV-vis spectrum, we can deduce that the degradation products of DB6 are likely to be a small amount of anilines, benzenes and their homologues, as well as other small molecules. The treatment of DB6 by AlCrFeMn greatly reduces the toxicity of DB6 solution and improves its biodegradability.

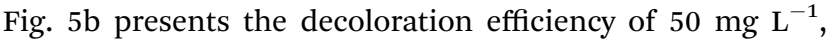
$100 \mathrm{mg} \mathrm{L}^{-1}$, and $200 \mathrm{mg} \mathrm{L}^{-1}$ DB6 solutions decolored by $0.5 \mathrm{~g}$ $\mathrm{L}^{-1}$ AlCrFeMn during the decoloration process at $25{ }^{\circ} \mathrm{C}$, initial $\mathrm{pH}=7$. The $200 \mathrm{mg} \mathrm{L}^{-1} \mathrm{DB} 6$ solution is completely decolored
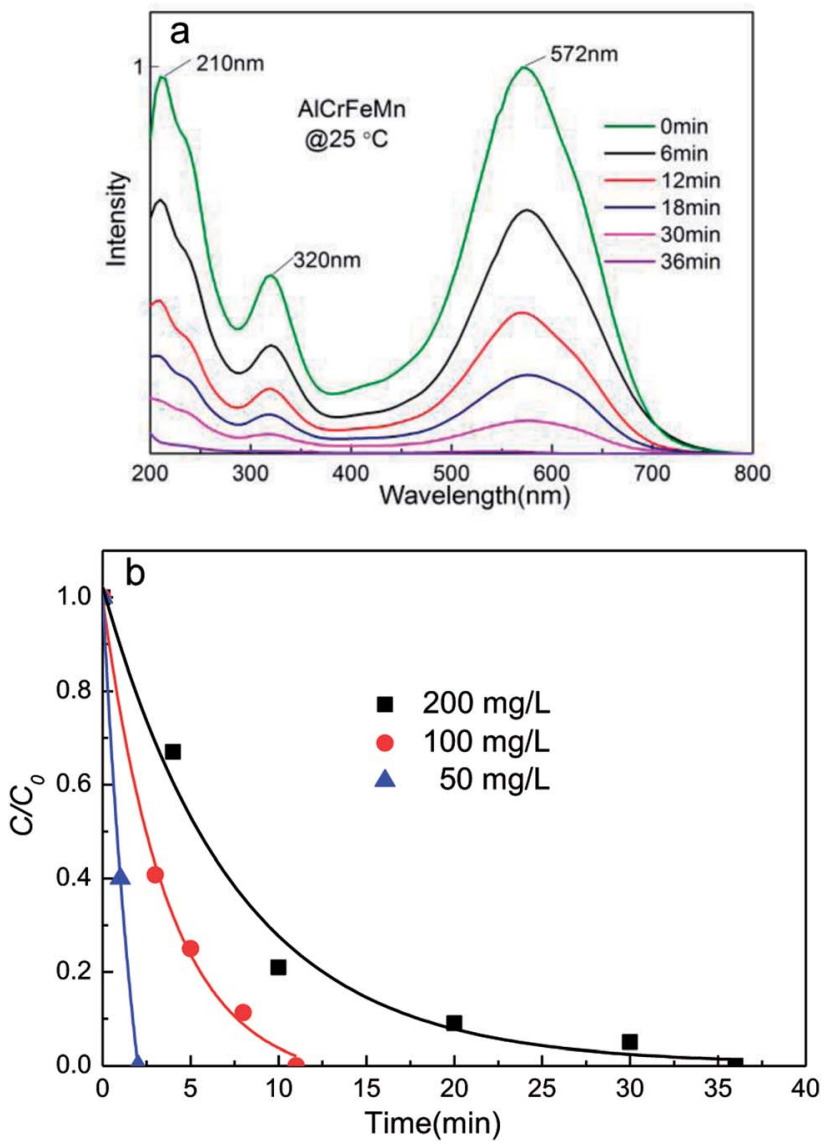

Fig. 5 (a) The UV-vis spectra and normalized concentrations of DB6 by $0.5 \mathrm{~g} \mathrm{~L}^{-1}$ AlCrFeMn during the decomposition process at $25^{\circ} \mathrm{C}$, initial $\mathrm{pH}=7$. (b) The decoloration curves of $50 \mathrm{mg} \mathrm{L}^{-1}, 100 \mathrm{mg} \mathrm{L}^{-1}$, and $200 \mathrm{mg} \mathrm{L}^{-1}$ DB6 degraded by $0.5 \mathrm{~g} \mathrm{~L}^{-1}$ AlCrFeMn during the decomposition process at $25^{\circ} \mathrm{C}$, initial $\mathrm{pH}=7$. 


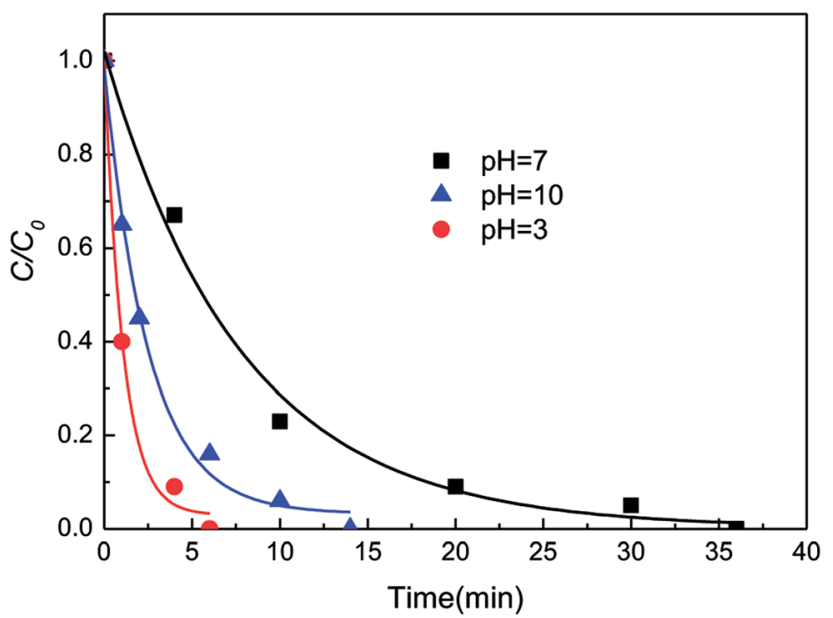

Fig. 6 The decoloration efficiency at different $\mathrm{pH}$ values $(\mathrm{pH}=3,7,10)$.

by AlCrFeMn within $7.5 \mathrm{~min}$. The $50 \mathrm{mg} \mathrm{L}{ }^{-1}$ and $100 \mathrm{mg} \mathrm{L}^{-1}$ DB6 solution were completely decolored by AlCrFeMn in only $2.4 \mathrm{~min}$ and $3.7 \mathrm{~min}$, respectively. Evidently, the higher the concentration of DB6, the longer it requires to be decolored.

3.4.2. Effect of different $\mathbf{p H}$ values. Most zero-valent metals would only be available in acidic or neutral environments. ${ }^{33}$ Slight variation of the $\mathrm{pH}$ value of solution can significantly change decoloration efficiency. Azo dye wastewater is usually alkaline and sometimes it is acidic. ${ }^{32}$ To evaluate the effect of $\mathrm{pH}$ values on the decomposition process, the decoloration experiments were carried out at $\mathrm{pH}=3,7$, and 10 . To examine the effect of $\mathrm{pH}$ level, solutions with $\mathrm{pH}=3$ and $\mathrm{pH}=10$ were prepared by adding $0.1 \mathrm{M} \mathrm{HCl}$ solution and $0.1 \mathrm{M} \mathrm{NaOH}$ solution, respectively. As shown in Fig. 6, the AlCrFeMn dosage was $0.5 \mathrm{~g} \mathrm{~L}^{-1}$ and the concentration of the dye was $200 \mathrm{mg} \mathrm{L}^{-1}$. Under acidic conditions, the decoloration efficiency of DB6 is better than that under alkaline conditions, and decoloration efficiency under alkaline conditions is better than that under neutral conditions.

Nascent hydrogen $([\mathrm{H}])$ is a kind of rapid reduction agent, which has been found to reduce various organics faster than direct electron transfer. ${ }^{34}$ However, the production of $[\mathrm{H}]$ is suppressed during the reaction under neutral or alkaline conditions. Thus, the decolorization efficiency of DB6 by AlCrFeMn in acidic environments is higher than that of DB6 under neutral or alkaline conditions. Under alkaline conditions, hydroxides are likely to be produced in the solution, such as $\mathrm{Fe}(\mathrm{OH})_{3}$ or $\mathrm{Al}(\mathrm{OH})_{3}$. These hydroxides have a strong adsorption capacity, and can adsorb to a large number of dye molecules and precipitate. So, due to the adsorption of hydroxides, the decolorization efficiency under alkaline environments is higher than that under neutral conditions, but lower than that under acidic conditions due to the strong $[\mathrm{H}]$ effect.

3.4.3. Effect of temperatures. Fig. 7a shows the normalized concentrations as a function of treatment times at different temperatures ranging from 25 to $55{ }^{\circ} \mathrm{C}$ of the decoloration of DB6 by AlCrFeMn. The plot of $\left(\ln t_{0}\right) v s$. (1000/ $R T$ ) for estimation of activation energy of decoloration of DB6 by AlCrFeMn is shown in Fig. 7b (initial $\mathrm{pH}=7,0.5 \mathrm{~g} \mathrm{~L}^{-1}$ AlCrFeMn). For ordinary thermal reactions, the activation energy is usually between 60 and $250 \mathrm{~kJ} \mathrm{~mol}^{-1}$; for the reaction of AlCrFeMn decolorizing azo dye DB6, the activation energy is just $54.6 \mathrm{~kJ} \mathrm{~mol}^{-1}$. Our results imply that the decoloration of DB6 by AlCrFeMn requires a relatively low energy. Based on the obtained kinetic rate constants at different temperatures, the activation energy $\left(\Delta E, \mathrm{~kJ} \mathrm{~mol}^{-1}\right)$ of the decoloration process of DB6 by AlCrFeMn can be obtained according to the equation:

$$
t_{0}=\tau_{0} \exp (\Delta E / R T)
$$

where $\tau_{0}$ is a time pre-factor and $R$ is the gas constant, $\Delta E$ is the activation energy, $t_{0}$ is the time when the intensity decreases to $\mathrm{e}^{-1}$ of the initial condition. ${ }^{27}$

\subsection{Characterization of samples after decoloration}

3.5.1. SEM and EDS analysis of AlCrFeMn powder after degradation. Fig. 8a shows that AlCrFeMn powders are uniformly distributed without significant aggregation after the reaction and Fig. 8b demonstrates that the surface morphology of AlCrFeMn particles after reaction resemble nanobristles uniformly distributed on the surface. This explicitly indicates
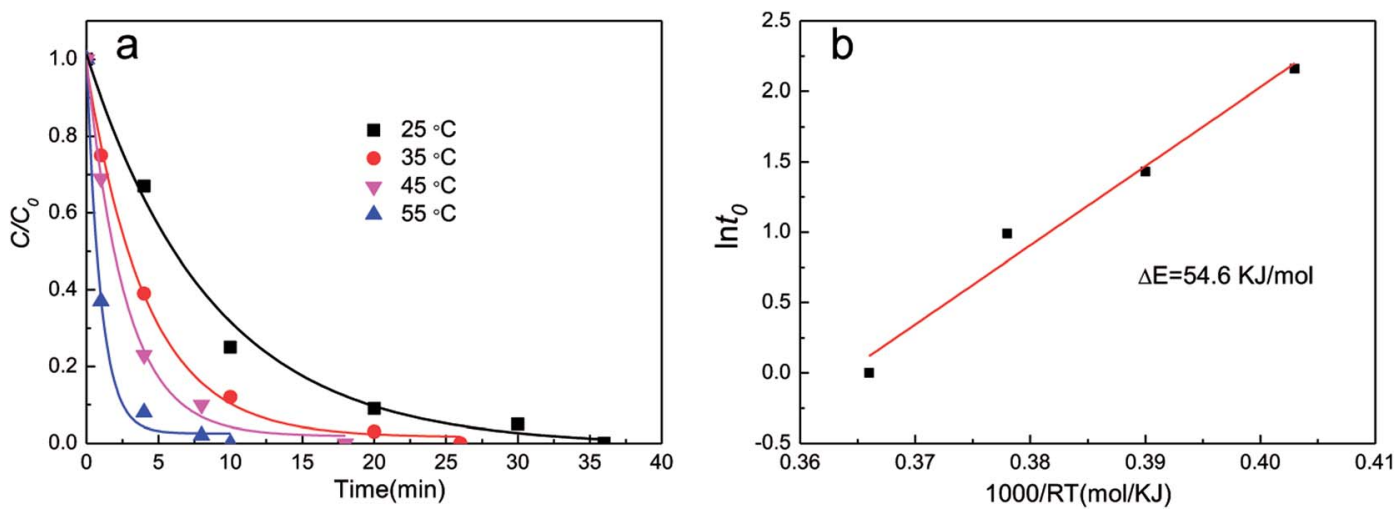

Fig. 7 (a) The normalized concentrations as a function of treatment times at different temperatures ranging from 25 to $55^{\circ} \mathrm{C}$ of decoloration of DB6 by AlCrFeMn. (b) Plot of ( $\left.\ln t_{0}\right)$ vs. $(1000 / R T)$ for estimation of the activation energy of decoloration of DB6 by AlCrFeMn, (initial pH $=7,0.5 \mathrm{~g}$ $\mathrm{L}^{-1} \mathrm{AlCrFeMn).}$ 
homogenous corrosion on the surface and the nanoscale surface features provide more active sites for the reaction to proceed and thus improves the decoloration efficiency. As presented in Fig. 8c, the EDS analysis shows that these nanobristles are mainly composed of $\mathrm{Al}, \mathrm{Cr}, \mathrm{Fe}, \mathrm{Mn}$ and $\mathrm{O}$ elements, but the oxygen content is particularly high. The $\mathrm{pH}$ value of DB6 solution after being completely degraded by AlCrFeMn is about 9.2, which means that the solution is alkaline after decoloration. As shown in Fig. 8d, the nanobristles mainly consist of oxides and hydroxides such as $\mathrm{Al}_{2} \mathrm{O}_{3}, \mathrm{Fe}_{3} \mathrm{O}_{4}, \mathrm{MnO}, \mathrm{Al}(\mathrm{OH})_{3}$, and $\mathrm{Fe}(\mathrm{OH})_{3}$.

3.5.2. TEM analysis of AlCrFeMn powder after degradation. As can be seen from Fig. 9, the powder shows the presence of many nanoscale whiskers on the surface, which corresponds to the SEM result of AlCrFeMn. On the one hand, nano whiskers show that the powder surface is uniformly corroded, and on the other hand, some degradation products are attached to the surface of the powders.

3.5.3. ICP analysis. The concentrations of $\mathrm{Al}, \mathrm{Cr}, \mathrm{Fe}$, and Mn ions left in the aqueous solution are 0.016, 0.013, 0.019, and $0.1495 \mathrm{ppm}$, respectively, which are close to the minimum detection values of the instrument. The concentrations of each ion indicate that AlCrFeMn powders do not cause secondary pollution after decoloration, which is ideal for environmental protection.
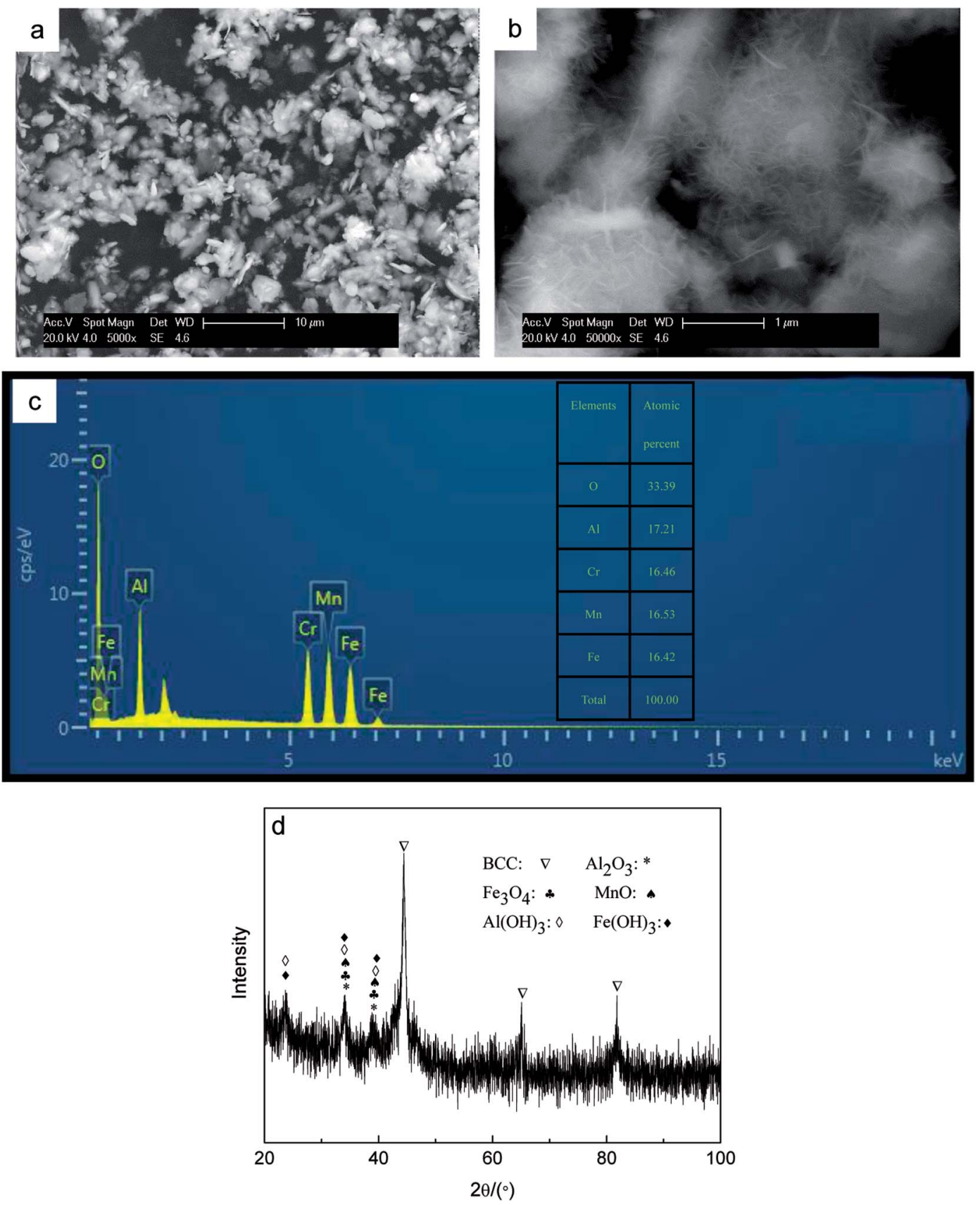

Fig. 8 (a) and (b) The SEM images of AlCrFeMn HEA after decoloration (c) the EDS analysis result of the actual compositions of AlCrFeMn HEA after decoloration (d) X-ray diffraction curve of AlCrFeMn HEA after decoloration. 


\section{a}

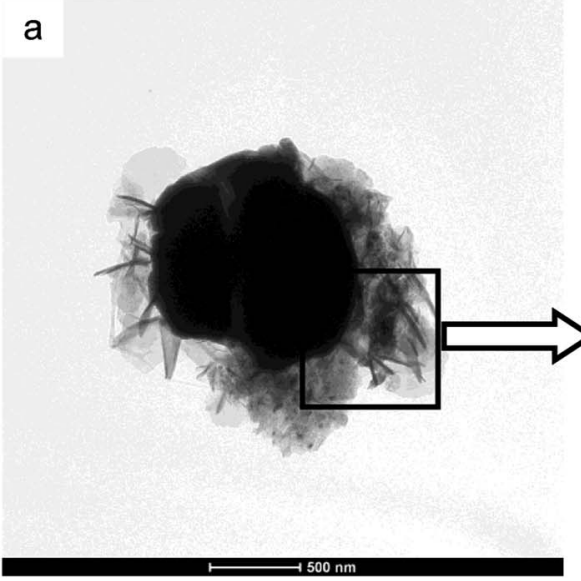

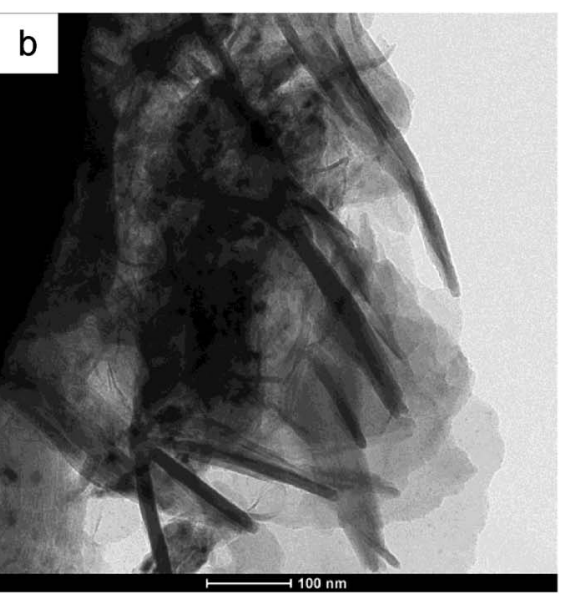

Fig. 9 (a) and (b) The TEM images of AlCrFeMn HEA after decoloration.

\subsection{Decoloration mechanism}

The relationship between the dye concentrations and the decoloration times is not a positive proportion. Through the nonlinear curve fitting, it can be found that the decolorization process of DB6 by AlCFeMn is in good agreement with the pseudo-first-order exponential decay kinetics as follows:

$$
I=I_{0}+I_{1} \exp \left(-t / t_{0}\right)
$$

where $I$ is the normalized intensity of concentration, $I_{0}$ and $I_{1}$ are fitting constants, $t$ is the reaction time and $t_{0}$ is the time when the intensity decreases to $\mathrm{e}^{-1}$ of the initial condition..$^{35}$

AlCrFeMn HEA show excellent performance in the decoloration of DB6. There are several factors discussed as follows. (1) Firstly, all of the zero-valent metals, $\mathrm{Al}, \mathrm{Cr}, \mathrm{Fe}$, and $\mathrm{Mn}$, are easily reduced. (2) The second reason is the reduction of $[\mathrm{H}]$ produced by the reaction between acid and metals. The quick transfer of electrons between the metals could produce a large number of $[\mathrm{H}]$ around the active sites, i.e., the electrons derived from the metals are captured by protons to generate nascent hydrogen ([H]). (3) Compared with ZVI, due to the special alloy component, the surface of the BM AlCrFeMn powders appear electrochemically inhomogeneous and form a large number of tiny galvanic cells between the elements such as $\mathrm{Al}-\mathrm{Fe}, \mathrm{Al}-\mathrm{Cr}$, $\mathrm{Mn}-\mathrm{Fe}$, and $\mathrm{Cr}-\mathrm{Fe}$. These tiny galvanic cells in AlCrFeMn act as the electron donors during the decoloration process that lose $\mathrm{e}^{-}$, and $\mathrm{H}_{2} \mathrm{O}$ provides $\mathrm{H}^{+}$. One " $-\mathrm{N}=\mathrm{N}-$ " " bond of the azo dye receives four $\mathrm{H}^{+}$and four $\mathrm{e}^{-}$and forms two " $-\mathrm{NH}_{2}$ ". (4) The fourth reason is that the combination of the unique crystal structure with severe lattice distortion and residual stress stored plastic deformation energy is responsible for the excellent capacity of HEAs in degrading azo dyes. The unique solid solution structure of HEAs virtually is in a non-equilibrium state that leads to HEAs possessing higher potential energy and more active sites than those in conventional alloys.

\section{Conclusions}

The efficiency and reaction kinetics of AlCrFeMn successfully fabricated by ball-milling for degrading organic chemicals were systematically investigated by evaluating its decolorization efficiency for azo dye DB6. The prominent decolorization performance of AlCrFeMn in the decoloration process of DB6 is attributed to redox reactions, special alloy composition, and unique crystal structure. The BM HEAs are promising and efficient materials for industrial wastewater treatment. BM AlCrFeMn HEA shows excellent performance in the decoloration of DB6, 3 times faster than BM MgZn-based glassy powders and $\mathrm{BM}$ AlCoCrTiZn. Dye concentrations, initial $\mathrm{pH}$ values and initial temperatures all have great influence on the decolorization efficiency of AlCrFeMn. As the dye concentrations and $\mathrm{pH}$ increase, the degradation rate of AlCrFeMn decreases, but as the temperatures increase, the degradation rate of AlCrFeMn increases. This study provides new insights for developing functional applications of HEAs.

\section{Conflicts of interest}

There are no conflicts to declare.

\section{Acknowledgements}

This study was supported by the National Natural Science Foundation of China (Grant No. 51671056), Jiangsu Key Laboratory for Advanced Metallic Materials (Grant No. BM2007204).

\section{Notes and references}

1 Y. Liu, H. Tian and A. Si, Plasma Chem. Plasma Process., 2012, 32, 597-607.

2 J. H. Ramirez, F. J. Maldonado-Hódar, A. F. Pérez-Cadenas, C. Moreno-Castilla, C. A. Costa and L. M. Madeira, Appl. Catal., B, 2007, 75, 312-347.

3 A. D. Bokare, R. C. Chikate, C. V. Rode and K. M. Paknikar, Environ. Sci. Technol., 2007, 41, 7437-7451.

4 S. D. Kalme, G. K. Parshetti, S. U. Jadhav and S. P. Govindwar, Bioresour. Technol., 2007, 98, 1405-1416.

5 R. V. Solomon, I. S. Lydia and J. P. Merlin, J. Iran. Chem. Soc., 2012, 9, 101-115. 
6 J. Fan, Y. Guo, J. Wang and M. Fan, J. Hazard. Mater., 2009, 166, 904-917.

7 N. Ertugay and F. N. Acar, Arabian J. Chem., 2017, 10, S1158S1169.

8 H. Lv, H. Zhao, T. Cao, L. Qian, Y. Wang and G. Zhao, J. Mol. Catal. A: Chem., 2015, 400, 81-90.

9 R. Patel and S. Suresh, J. Hazard. Mater., 2006, 137, 17291740.

10 Y. Su, Z. Wu and Y. Wu, J. Mater. Chem. A, 2015, 3, 85378549.

11 E. S. Aazam and R. M. Mohamed, J. Alloys Compd., 2013, 577, 550-561.

12 S. Chen, G. Yang and S. Luo, J. Mater. Chem. A, 2017, 5, 2739.

13 P. Singla, M. Sharma and O. P. Pandey, Appl. Phys. A: Mater. Sci. Process., 2014, 116, 371-380.

14 N. Divya, A. Bansal and A. K. Jana, Int. J. Environ. Sci. Technol., 2013, 10, 1265-1274.

15 A. Pandey, P. Singh and L. Iyengar, Int. Biodeterior. Biodegrad., 2007, 59, 73-82.

16 J. Wang, Y. Liu, M. Chen, G. Xie, D. V. Louzguine-Luzgin, A. Inoue and J. H. Perepezko, Adv. Funct. Mater., 2012, 22, 2567-2580.

17 H. Kusic, N. Koprivanac and L. Srsan, J. Photochem. Photobiol., A, 2006, 181, 195-208.

18 C. Zhang, Z. Zhu, H. Zhang and Z. Hu, Chin. Sci. Bull., 2011, 56, 3988-3996.

19 H. Liu, G. Li, J. Qu and H. Liu, J. Hazard. Mater., 2007, 144, 180-191.

20 S. Chang, K. Wang, S. Chao, T. Peng and L. Huang, J. Hazard. Mater., 2009, 166, 1127-1238.
21 H. Shu, M. Chang, C. Chen and P. Chen, J. Hazard. Mater., 2010, 184, 499-510.

22 Y. Keum and Q. X. Li, Chemosphere, 2004, 54, 255-267.

23 C. Lee and T. Shun, Mater. Charact., 2016, 114, 179-190.

24 R. R. Eleti, V. Raju, M. Veerasham, S. R. Reddy and P. P. Bhattacharjee, Mater. Charact., 2018, 136, 286-298.

25 H. Zhou, Y. Su, N. Liu, F. Kong, X. Wang, X. Zhang and Y. Chen, Mater. Charact., 2018, 138, 10-22.

26 Z. Cai, G. Jin, X. Cui, Z. Liu, W. Zheng, Y. Li and L. Wang, Mater. Charact., 2016, 120, 229-239.

27 Z. Y. Lv, X. J. Liu, B. Jia, H. Wang, Y. Wu and Z. P. Lu, Sci. Rep., 2016, 6, 34213-34225.

28 Y. Tang, Y. Shao and N. Chen, RSC Adv., 2015, 5, 3403234043.

29 P. Wang, J. Q. Wang and H. Li, J. Alloys Compd., 2017, 701, 759-767.

30 W. B. Mbarek, M. Azabou and E. Pineda, RSC Adv., 2017, 7, 12620-12628.

31 D. O'Carroll, B. Sleep and M. Krol, Adv. Water Resour., 2013, 51, 104-122.

32 J. Wang, Y. Liu, M. Chen, D. V. Louzguine-Luzgin, A. Inoue and J. H. Perepezko, Sci. Rep., 2012, 2, 418-426.

33 S. H. Chang, S. H. Chuang and H. C. Li, J. Hazard. Mater., 2009, 166, 1279-1288.

34 X. D. Qin, Z. W. Zhu, G. Liu, H. M. Fu, H. W. Zhang, A. M. Wang, H. Li and H. F. Zhang, Sci. Rep., 2016, 5, 18226-18237.

35 C. Zhang, H. Zhang, M. Lv and Z. Hu, J. Non-Cryst. Solids, 2010, 356, 1703-1712. 